\title{
Effect of oligomers on structural and functional state of biomembranes
}

\author{
Zaytseva O., Viktor Zhukov, Rezunenko Y., Telegin V, Knigavko V., Risovanaya L. \\ Kharkiv National Medical University, Biochemistry Department \\ Email address: \\ gramatyuk@ukr.net (Zhukov V.)
}

\section{To cite this article:}

Zaytseva O., Viktor Zhukov, Rezunenko Y., Telegin V, Knigavko V., Risovanaya L.. Effect of Oligomers on Structural and Functional State of Biomembranes. Science Journal of Chemistry. Vol. 1, No. 2, 2013, pp. 26-28. doi: 10.11648/j.sjc.20130102.13

\begin{abstract}
The effect of a new group of oligomers on the structural and functional state of erythrocytes, lymphocytes, hepatocytes, splenocytes membranes of rats under subacute experiment conditions was investigated. It is established that the oligomers are able to alter the membrane physical-chemical properties and disrupt the structural and metabolic processes that underlie the formation of pathological states.
\end{abstract}

Keywords: Membranes, Phospholipids, Lipid Peroxidation, Ion Transport, Fluorescent Probes

\section{Introduction}

Oligomers based on ethylene and propylene oxides widely are used in various sectors of the economy. Large volumes of their production create a potential hazard to human health [1-6, 14].

Particular attention is forecasting the biological activity of new groups of compounds acquiring toxicodynamics, toxicokinetics and biotransformation research, in which the leading role belongs to the study of structural and functional state of cell membranes [7-9, 16].

The purpose of this study was to investigate the influence of a new group of oligomers based on ethylene and propylene oxides on the structural and functional state of erythrocytes, lymphocytes, splenocytes and hepatocytes membranes in the subacute experiment.

\section{Materials and Research Methods}

Work was realized on Wistar rats weighing 150-180 g, which daily for 1.5 months with the help of the probe oligomers: polyoxipropyleneglykol L-202, polyoxipropylenetetramethilenglykol L-1102-4-80, polyoxiethyleneoxipropylenethriols L-3003 -2-60 and L4003-2-20 were injected at doses of 1/10, 1/100, 1/1000 DL50. L-202 has DL50 $=3040.0 \mathrm{mg} / \mathrm{kg} ; \mathrm{L}-1102-4-80$ has $\mathrm{DL} 50=4800.0 \mathrm{mg} / \mathrm{kg} ; \mathrm{L}-3003-2-60$ has $\mathrm{DL} 50=3210.0$ $\mathrm{mg} / \mathrm{kg} ; \mathrm{L}-4003-2-20$ has DL50 $=5870.0 \mathrm{mg} / \mathrm{kg}$ of animal weight. In each group, there were 10-15 animals.

The intact rats not injected by oligomers served as a control group. The research program included the determination of phospholipid fractions, ion permeability, viscosity, charge and polarity of the of erythro-, hepato-, spleno- and lymphocytes membranes. Analysis of the membrane phospholipids fractions was performed by twodimensional chromatography[10, 15].

Identification of phospholipids was performed according to standard solutions and quality detectors. To detect violations of the membrane permeability we used method for measuring the rate of $\mathrm{K}+$ ions going into medium without $\mathrm{K}+$ with help of glass ion-selective electrode twice: the rate of spontaneous going and the velocity of $\mathrm{K}+$ ion yield induced by the valinomycin [11-12].

Changes in membrane viscosity, polarity and charge under the influence of oligomers was studied using fluorescent probes. The intensity of free radical processes and lipid peroxidation (LPO) as significant indices of structural-functional state of the membranes was studied by the intensity of luminol- and H2O2-dependent biochemiluminescence (BChl), the accumulation of malondialdehyde (MDA) and diene conjugates (DC) [13].

Status of oxidative modification of proteins was assessed by levels the aldo- and ketohydrozones. Statistical analysis was performed by the Student-Fisher t-criterion.

\section{Results of Research and their Discussion}

It is known that many xenobiotics can stimulate free radical processes and lipid peroxidation, create the 
accumulation in organs and tissues the peroxides, hydroperoxides and other reactive radicals having membrane disturbing property. Changes in the state of homeostasis is accompanied by shifts in metabolic processes in the organism, for study of which we used BChl method as the most sensitive. Oligomers in doses of $1 / 100$ and $1 / 1000 \mathrm{DL}_{50}$ increased $\mathrm{BChl}$ intensity of internal organs homogenates, as well as the contents of MDA and DC in the liver and serum, the contents of aldo- and ketohydrozones, which indicates stimulation of oxidative modification of proteins. The dose of $1 / 10000 \mathrm{DL}_{50}$ was inoperative.

Taking into account the oligomers contain hydrophilic and hydrophobic radicals, we can assume a priority of their influence on protein and lipid membrane structure. In this regard, determined the percentage contents of phosphatidylcholine (PC), phosphatidylserine (PS), phosphatidylethanolamyne (PEA), lizophosphatidylethanolamyne (LPEA), lysophosphatidylcholine (LPC), phosphatidic acid (PA), cardiolipin (CL), and sphingomyelin (SM) in erythrocytes, leukocytes, splenocytes and hepatocytes. Oligomers in doses of $1 / 10$ and $1 / 100 \mathrm{DL}_{50}$ changed the percentage of almost all the studied phospholipids fractions. Common and characteristic change is the emergence of lizoforms, which is evidence of violations of the membrane structure, accompanied by the formation of highly toxic compounds.

However, the oligomers didn't violate the percentage content of PS in leukocytes, splenocytes, hepatocytes, whereas its content in erythrocytes was significantly decreased.

The most significant changes in the distribution of phospholipidic fractions are determined in red blood cells that is explained, apparently, by a low level of repair and synthetic processes in these nuclear-free blood cells. By the end of subacute experience under the oligomers influence there was the decrease of fluidity of the erythrocytes cytoplasmic membranes compared with control. This process was significant in the lipid bilayer and in the area of protein-lipid contacts. Depending on the dose and duration of exposure of oligomers membrane fluidity was reduced up to $40 \%$. In lymphocytes reduction of fluidity mainly was in lipid bilayer and the maximum was under dose of $1 / 100 \mathrm{DL}_{50}$.

In addition, oligomers increased the immersion of proteins in lipid bilayer of erythrocytes and lymphocytes membranes, which can lead to a breach of the membranebound enzymes activity. More significant changes in membrane fluidity and the immersion of proteins in the lipid matrix in red blood cells, compared with those in lymphocytes, are connected, apparently, with a low potential of the repair of damaged membranes. The fluorescence intensity of 1,8-ANC probe in lymphocytes and erythrocytes, which reflects changes in the surface charge of membranes, significantly decreased in the experimental groups at $32-94 \%$, depending on the dose oligoethers. This can be due to increased polarity of the membrane as a result of dehydration of protein molecules and the accumulation of water in the membrane structures. All oligoethers in doses of $1 / 100$ and $1 / 1000 \mathrm{DL}_{50}$ increased spontaneous and induced by valinomycin $\mathrm{K}^{+}$ion yield of the red blood cells, that is evidence of the violation of the structural and functional membrane organization and, consequently, the ion transport.

Changing the phospholipid fractions distribution, accompanied by an increase of their lizoforms, and violation of physical and chemical parameters of the state of plasma membranes were the structural and metabolic basis of changes in transport function of biological membranes, which implies a violation of the metal ions flow and nuclear-cytoplasmic interactions.

\section{Conclusive}

Thus, the investigated group of oligomers has a unidirectional effect on the structural and functional state of membranes, accompanied by a change in their physicochemical properties - polarity, charge, permeability, viscosity, hydrophobic volume, which can lead to qualitative and quantitative changes in the activity of metabolic processes in the structural and functional units of cells and disintegration of the nuclear-cytoplasmic interactions that underlie the formation of pathological conditions. The dose of $1 / 10000 \mathrm{DL}_{50}$ does not effect on the physicochemical and metabolic properties of the membranes.

\section{References}

[1] Alon R, Grabovsky V, Feigelson S. Chemokine induction of integrin adhesiveness on rolling and arrested leukocytes local signaling events or global stepwise activation? Microcirculation. 2003;10:297-311.

[2] Baltus T, Weber KS, Johnson Z, Proudfoot AE, Weber C. Oligomerization of RANTES is required for CCR1mediated arrest but not CCR5-mediated transmigration of leukocytes on inflamed endothelium. Blood. 2003;102:1985-1988.

[3] Gregory KJ, Dong EN, Meiler J, Conn PJ. Allosteric modulation of metabotropic glutamate receptors structural insights and therapeutic potential. Neuropharmacology . 2011;60: 66-81.

[4] Carpino PA, Goodwin B. Diabetes area participation analysis a review of companies and targets described in the 2008 - 2010 patent literature. Expert Opin Ther Pat . 2010;20:1627-1651.

[5] Duma L, Haussinger D, Rogowski M, Lusso P, Grzesiek S. Recognition of RANTES by extracellular parts of the CCR5 receptor. J Mol Biol. 2007;365:1063-1075.

[6] Vasseur C, Rodien P, Beau I, Desroches A, Gerard C, de Poncheville L, Chaplot S, Savagner F, Croue A, Mathieu E, Lahlou N, Descamps P, Misrahi M. A chorionic gonadotropin-sensitive mutation in the folliclestimulating hormone receptor as a cause of familial gestational 
spontaneous ovarian hyperstimulation syndrome. N Engl J Med . 2003;349: 753-759.

[7] Dragun D, Philippe A, Catar R, Hegner B. Autoimmune mediated Gprotein receptor activation in cardiovascular and renal pathologies. Thromb Haemost . 2009;101:643-648.

[8] Vischer HF, Vink C, Smit MJ. A viral conspiracy hijacking the chemokine system through virally encoded pirated chemokine receptors. Curr Top Microbiol Immunol. 2006;303:121-154.

[9] Katano H, Sata T. Human herpesvirus 8 virology epidemiology and related diseases. Jpn J Infect Dis . 2000;53:137-155.

[10] Penela P, Murga C, Ribas C, Tutor AS, Peregrin S, Mayor F Jr. Mechanisms of regulation of $\mathrm{G}$ protein-coupled receptor kinases (GRKs) and cardiovascular disease. Cardiovasc Res . 2006;69:46-56.

[11] Lombardi MS, Kavelaars A, Heijnen CJ. Role and modulation of $\mathrm{G}$ protein-coupled receptor signaling in inflammatory processes. Crit Rev Immunol . 2002;22:141-
163.

[12] Shichida Y, Imai H. Visual pigment G-protein-coupled receptor for light signals. Cell Mol Life Sci . 1998;54:12991315 .

[13] Lappano R, Maggiolini M. G protein-coupled receptors novel targets for drug discovery in cancer. Nat Rev Drug Discov . 2011;10:47-60.

[14] Stone LS, Molliver DC. In search of analgesia emerging poles of GPCRs in pain. Mol Interv. 2009;9:234-251.

[15] Rasmussen SG, DeVree BT, Zou Y, Kruse AC, Chung KY, Kobilka TS, Thian FS, Chae PS, Pardon E, Calinski D, Mathiesen JM, Shah ST, Lyons JA, Caffrey M, Gellman SH, Steyaert J, Skiniotis G, Weis WI, Sunahara RK, Kobilka BK. Crystal structure of the beta(2) adrenergic receptor-Gs protein complex. Nature . 2011;477:549-555.

[16] Chung KY, Rasmussen SG, Liu T, Li S, DeVree BT, Chae PS, Calinski D, Kobilka BK, Woods VL, Jr., Sunahara RK. Conformational changes in the $\mathrm{G}$ protein Gs induced by the beta2 adrenergic receptor. Nature . 2011;477:611-615. 